\title{
Negative-type Chemically Amplified Photosensitive Semi-alicyclic Polybenzoxazole via Acid-catalyzed Electrophilic Substitution
}

\author{
Ken-ichi Fukukawa, Yuji ShIBASAKI, and Mitsuru UedA ${ }^{\dagger}$ \\ Department of Organic and Polymeric Materials, Graduate School of Science and Engineering, \\ Tokyo Institute of Technology, 2-12-1, H-120, O-okayama, Meguro-ku, Tokyo 152-8552, Japan
}

(Received September 6, 2004; Accepted November 1, 2004; Published February 15, 2005)

\begin{abstract}
A negative-type photosensitive semi-alicyclic polybenzoxazole (Nega-PSPABO) based on poly(o-hydroxy amide) containing an adamantyl unit (PAHA) and oxybis(3,4-dihydroxymethyl)benzene (OBHB) as a cross-linker, and a photoacid generator, (5-propylsulfonyloxyimino-5H-thiophen-2-ylidene)-(2-methylphenyl)acetonitrile (PTMA) has been developed. PAHA with a weight average molecular weight of 24,100 was prepared from 1,3-adamantanedicarbonyl chloride (ADC) and 4,4'-(hexafluoroisopropylidene)bis(o-aminophenol) (6FAP) in the presence of lithium chloride in $N$-methyl pyrrolidinone (NMP) at $0{ }^{\circ} \mathrm{C}$ for $12 \mathrm{~h}$. The photosensitive polymer based on $85 \mathrm{wt} \%$ PAHA, $10 \mathrm{wt} \%$ OBHB, and $5 \mathrm{wt} \%$ PTMA showed a sensitivity of $D_{0.5}=14.4 \mathrm{~mJ} / \mathrm{cm}^{2}$ and a contrast of 2.4 when it was exposed to a $365 \mathrm{~nm}$ light (i-line) and developed with a $2.38 \mathrm{wt} \%$ aqueous tetramethylammonium hydroxide solution (TMAHaq) at $25^{\circ} \mathrm{C}$. A fine negative image of $7 \mu \mathrm{m}$ line-and-space pattern was also printed in the film which was exposed to $80 \mathrm{~mJ} / \mathrm{cm}^{2}$ of i-line by contact-printing mode. The negative image in PAHA was converted to the corresponding $\mathrm{PABO}$ pattern image by thermal treatment without pattern deformation. The average refractive index of Nega-PSPABO was 1.542 from which the dielectric constant estimated was 2.62 at $1 \mathrm{MHz}$.
\end{abstract}

[DOI 10.1295/polymj.37.74]

KEY WORDS Chemically Amplified Photosensitive Polymer / Semi-aromatic Polybenzoxazole / Photoresist / Cross-linker / Electrophilic Substitution / Negative Image / Low Dielectric Constant /

Photosensitive polybenzoxazoles (PSPBOs) $)^{1-11}$ have been used as protection and insulation layers for very large scale integration circuits (VLSIs) and multichip modules for computers owing to their high thermal stability and excellent mechanical and electrical properties. ${ }^{12} \mathrm{Up}$ to now PSPBO based on poly $(o-$ hydroxy amide) (PHA) derived from 4,4'-(hexafluoroisopropylidene)bis(o-aminophenol) (6FAP) and 4,4'oxybis(benzoic acid) derivatives with a photosensitive compound is widely used. However, PSPBO having a lower dielectric constant and higher transparency is required to increase the circuit speed and to maximize the throughput of wafers in exposure tools.

In a preceding paper, ${ }^{13}$ we reported the synthesis of semi-alicyclic PHA (PAHA) with high transparency (99\% T @ $365 \mathrm{~nm}$ ) and the corresponding PBO (PABO) having the low dielectric constant $(\varepsilon=$ $2.55)$. PAHA was then employed as a new positivetype photosensitive PABO (Posi-PSPABO) consisting of PAHA, 1,3,5-tris[(2-vinyloxy)ethoxy]benzene (TVEB) as an acidolytic de-cross-linker, and diphenyliodonium-9,10-dimethoxyanthracene-2-sufonate (DIAS) as a photoacid generator in chemical amplification system. Posi-PSPABO shows high photosensitivity $\left(40 \mathrm{~mJ} / \mathrm{cm}^{2}\right)$ because of the introduction of an adamantyl unit, which is effective in decreasing both molecular density and conjugation in the main chain due to the bulkiness and the $s p^{3}$ character of carbons, respectively. The next target is to develop a negativetype chemically amplified PSPABO (Nega-PSPABO) using PAHA for expanding the image formation and improving the sensitivity.

As a cross-linker, 4,4'-methylenebis[2,6-di(hydroxymethyl)]phenol (MBHP, the structure is shown in Scheme 4) has been used extensively for negativetone chemically amplified photosensitive materials so far. ${ }^{14-16}$ Since the remained phenolic hydroxyl group in MBHP may increase dielectric constants of the films after the thermal treatment, a new cross-linker without phenol units are more desirable.

This article reports the development of a three-component Nega-PSPABO with high transparency and a low dielectric constant based on PAHA, oxybis(3,4dihydroxymethyl)benzene (OBHB) as a novel crosslinker, and (5-propylsulfonyloxyimino-5H-thiophen2-ylidene)-(2-methylphenyl)acetonitrile (PTMA) as a photoacid generator.

\section{EXPERIMENTAL}

\section{Materials}

Tetrahydrofuran (THF) was distilled from sodium

†To whom correspondence should be addressed (E-mail: mueda@ polymer.titech.ac.jp). 
metal and benzophenone ketyl. $N$-Methyl-2-pyrrolydinone (NMP) was dried over calcium hydride, distilled under reduced pressure, and stored over $4-\AA$ molecular sieves. 6FAP was purified by recrystallization from THF. ADC was prepared by reaction of 1,3-adamantenedicarboxylic acid with excess amounts of thionyl chloride, followed by recrystallization from $n$-hexane. A photoacid generator, PTMA, ${ }^{17}$ was kindly donated by Ciba Specialty Chemicals Co., Ltd. and was used without further purification. A cross-linker, MBHP, was prepared according to a reported procedure. ${ }^{18}$ The other reagents and solvents were used as received.

\section{Synthesis of Oxybis(3,4-phthalic acid dimethyl ester)} (2)

A solution of 4,4'-oxydiphthalic anhydride $\mathbf{1}$ $(7.82 \mathrm{~g}, 25.2 \mathrm{mmol})$ and sulfuric acid $(2 \mathrm{~mL})$ in methanol $(260 \mathrm{~mL})$ was refluxed for $24 \mathrm{~h}$. The solution was concentrated with a rotary evaporator, and then poured into water. After the aqueous solution was decanted, the precipitate was dissolved in THF $(80 \mathrm{~mL})$ and then added saturated aqueous sodium bicarbonate solution with stirring. The organic layer was separated with a separatory funnel, while the aqueous layer was extracted with THF/ether $(2 / 1, \mathrm{v} / \mathrm{v})(20 \mathrm{~mL} \times 3$ times). The combined organic solution was dried over magnesium sulfate anhydride, followed by evaporation. The residue was purified by recrystallization from isopropyl alcohol/hexane to give white crystals. The yield was $6.34 \mathrm{~g}(63 \%)$. Mp: $71-72{ }^{\circ} \mathrm{C}$. IR ( $\mathrm{KBr}$, $\left.v, \mathrm{~cm}^{-1}\right): 2954\left(\mathrm{CH}_{3}\right), 1720(\mathrm{C}=\mathrm{O}), 1292(\mathrm{Ph}-\mathrm{O}-\mathrm{Ph})$. ${ }^{1} \mathrm{H}$ NMR $\left(\mathrm{CDCl}_{3}, \delta, \mathrm{ppm}\right): 7.83(\mathrm{~d}, J=8.4 \mathrm{~Hz}, 2 \mathrm{H}$, $\operatorname{Ar}-\underline{\mathrm{H}}), 7.27(\mathrm{~d}, J=2.7 \mathrm{~Hz}, 2 \mathrm{H}, \operatorname{Ar}-\underline{\mathrm{H}}), 7.16(\mathrm{dd}$, $J=8.4,2.7 \mathrm{~Hz}, 2 \mathrm{H}, \mathrm{Ar}-\underline{\mathrm{H}}), 3.91\left(\mathrm{~s}, 12 \mathrm{H}, \mathrm{CH}_{3}\right)$. ${ }^{13} \mathrm{C}$ NMR (DMSO- $\left.d_{6}, \delta, \mathrm{ppm}\right): 167.9,167.2,158.8$, 135.8, 132.1, 127.0, 121.3, 119.4, 53.3, 53.1. Elemental anal. Calcd for $\mathrm{C}_{20} \mathrm{H}_{18} \mathrm{O}_{9}: \mathrm{C}, 59.70 ; \mathrm{H}, 4.51 ; \mathrm{O}$, 35.79; Found C, 60.03; H, 4.54; O, 35.43.

\section{Synthesis of Oxybis(3,4-dihydroxymethyl)benzene (OBHB)}

A solution of $2(10.5 \mathrm{~g}, 26.1 \mathrm{mmol})$ in dry THF $(180 \mathrm{~mL})$ was cooled with an ice-water bath. To this solution was added dropwise a solution of lithium aluminum hydride (LAH; $3.49 \mathrm{~g}, 92.0 \mathrm{mmol}$ ) in dry THF $(90 \mathrm{~mL})$ for $20 \mathrm{~min}$. The mixture was stirred for $24 \mathrm{~h}$ at room temperature. Ethyl acetate $(350 \mathrm{~mL})$ was added to the reaction mixture slowly to quench excess amount of $\mathrm{LAH}$, and the mixture was poured into water. Aqueous hydrochloric acid solution $(2 \mathrm{~N})$ was then added with stirring until the solution was slightly acidic. The organic layer was separated and the aqueous layer was extracted with ethyl acetate $(60 \mathrm{~mL} \times 3$ times). Then, the combined organic layer was washed with an aqueous sodium bicarbonate solution and dried over magnesium sulfate anhydride. The solvent was removed with a rotary evaporator and the solid residue was purified by column chromatography (ethyl acetate $/ \mathrm{THF}=6 / 1$ in volume), followed by recrystallization from $\mathrm{THF} /$ hexane to give white crystals. The yield was $3.88 \mathrm{~g}$ (51\%). Mp: 104.2-104.5 ${ }^{\circ} \mathrm{C}$. IR $\left(\mathrm{KBr}, v, \mathrm{~cm}^{-1}\right)$ : $3278(\mathrm{OH}), 2877\left(\mathrm{CH}_{2}\right)$, 1604 (Ar), 1245 (Ph-O-Ph). ${ }^{1} \mathrm{H}$ NMR (DMSO- $d_{6}, \delta$, ppm): 7.34 (d, $J=8.4 \mathrm{~Hz}, 2 \mathrm{H}, \mathrm{Ar}-\underline{\mathrm{H}}), 7.05(\mathrm{~d}, J=$ $2.4 \mathrm{~Hz}, 2 \mathrm{H}, \mathrm{Ar}-\underline{\mathrm{H}}), 6.83(\mathrm{dd}, J=8.4,2.4 \mathrm{~Hz}, 2 \mathrm{H}$, Ar- $\underline{\mathrm{H}}), 4.99(\mathrm{dt}, J=13.8,5.4 \mathrm{~Hz}, 4 \mathrm{H}, \mathrm{OH}), 4.50$ (dd, $J=15.6,5.1 \mathrm{~Hz}, \mathrm{CH}_{2}$ ). ${ }^{13} \mathrm{C}$ NMR (DMSO- $d_{6}, \delta$, ppm): 156.8, 142.8, 134.7, 129.5, 117.3, 117.1, 60.9, 60.7. Elemental anal. Calcd for $\mathrm{C}_{16} \mathrm{H}_{18} \mathrm{O}_{5}$ : C, 66.19; H, 6.25; O, 27.56; Found C, 66.50; H, 6.36; O, 27.14.

Synthesis of Adamantane-containing Poly(o-hydroxyamide) (PAHA) and the Corresponding Polybenzoxazole $(P A B O)$

PAHA was prepared by low temperature solution polycondensation of 6FAP and ADC in the presence of lithium chloride as reported in our previous paper. ${ }^{13,19}$ Number- and weight-average molecular weights $\left(M_{\mathrm{n}}, M_{\mathrm{w}}\right)$ were measured by GPC (DMF, polystyrene standards) to be 12,600 and 22,100 , respectively $\left(M_{\mathrm{w}} / M_{\mathrm{n}}=1.8\right)$. PABO was prepared from PAHA by thermal curing at elevated temperature up to $350^{\circ} \mathrm{C}$ under nitrogen.

\section{Dissolution Rate}

PAHA was dissolved in cyclohexanone at a concentration of $15 \mathrm{wt} \%$ to which was added OBHB (5$10 \mathrm{wt} \%$ of the total solid) and PTMA (5 wt $\%$ of the total solid). This photosensitive polymer film spin-cast from the solution on a silicon wafer was pre-baked at $100^{\circ} \mathrm{C}$ for $2 \mathrm{~min}$, and then exposed to a filtered superhigh-pressure mercury lamp at $365 \mathrm{~nm}$ (i-line), followed by post-exposure baking at a temperature $\left(120-140^{\circ} \mathrm{C}\right)$ for $5-10 \mathrm{~min}$. The exposed film was developed with $2.38 \mathrm{wt} \%$ of tetramethylammonium hydroxide (TMAHaq) solution at $25^{\circ} \mathrm{C}$. Dissolution rate $(\AA / s)$ of the film was determined from changes in the film thickness before and after the development.

\section{Photosensitivity}

A 2.2- $\mu \mathrm{m}$-thick photosensitive polymer film on a silicon wafer was exposed to i-line and then developed with $2.38 \mathrm{wt} \%$ of TMAHaq at $25^{\circ} \mathrm{C}$ for $10 \mathrm{~s}$, followed by rinsing with water. A characteristic curve was obtained by plotting a normalized film thickness as a function of exposure dose $\left(\mathrm{mJ} / \mathrm{cm}^{2}\right)$.

\section{Model Reaction for Cross-linking}

PAHA, $p$-methoxy benzyl alcohol (two equiv of a PAHA repeat unit) and $p$-toluenesulfonic acid mono- 


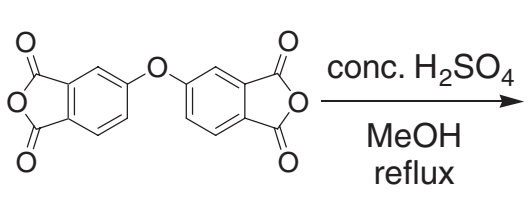

(1)<smiles>CCOC(=O)c1ccc(Oc2ccc(C(=O)OC)c(OC)c2)cc1C(=O)OCC</smiles>

(2)<smiles>OCc1ccc(Oc2ccc(CO)c(CO)c2)cc1CO</smiles>

OBHB

Scheme 1. Synthesis of OBHB.

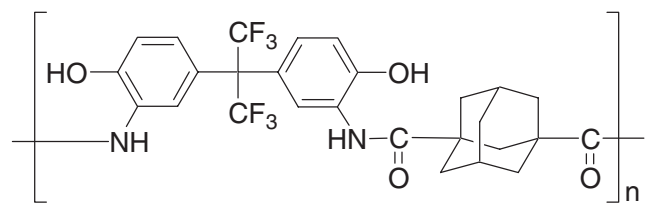

PAHA

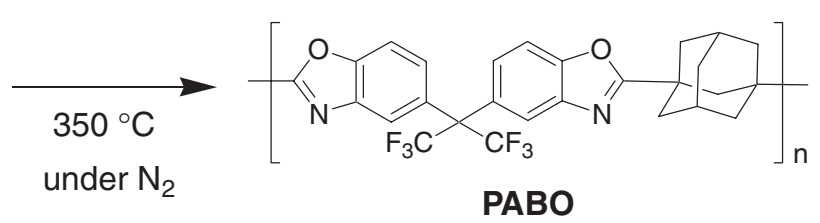

PABO

Scheme 2. Structure of PAHA and PABO.

hydrate (pTS; $10 \mathrm{wt} \%$ of PAHA) were dissolved in THF (as $15 \mathrm{wt} \%$ of PAHA solution). A film cast from the solution onto a laboratory dish was heated at $100^{\circ} \mathrm{C}$ and then $140^{\circ} \mathrm{C}$ for $10 \mathrm{~min}$ each, followed by vacuum drying at $50^{\circ} \mathrm{C}$ for $2 \mathrm{~h}$. A film without pTS was also prepared in the same procedure. Each sample was dissolved in DMSO- $d_{6}$ for the measurement of ${ }^{1} \mathrm{H}$ NMR spectroscopy.

\section{Measurements}

Fourier transferred infrared spectra (IR) were taken with a Horiba FT-210 spectrophotometer. ${ }^{1} \mathrm{H}$ and ${ }^{13} \mathrm{C}$ nuclear magnetic resonance (NMR) spectra were recorded on a BRUKER GPX300 $\left({ }^{1} \mathrm{H}\right.$ at $300 \mathrm{MHz}$ and ${ }^{13} \mathrm{C}$ at $75 \mathrm{MHz}$ ) spectrometer. Thermogravimetric analysis (TG) and differential scanning calorimetry (DSC) were performed on a Seiko TG/DTA 6300 and DSC 6200 , respectively at a heating rate $5^{\circ} \mathrm{C} /$ min under nitrogen stream. Number- and weight-average molecular weights $\left(M_{\mathrm{n}}, M_{\mathrm{w}}\right)$ were determined by a gel permeation chromatography (GPC) with a Tosoh HLC-8120 GPC system equipped with polystyrene gel columns (TSK GELs; $\mathrm{GMH}_{\mathrm{HR}}-\mathrm{M}$, and $\mathrm{GMH}_{\mathrm{HR}^{-}}$ L) at $40^{\circ} \mathrm{C}$ in DMF (containing $0.01 \mathrm{M}$ of $\mathrm{LiBr}$ ) at a flow rate of $1.0 \mathrm{~mL} / \mathrm{min}$, calibrated with polystyrene standards. Film thickness on silicon wafers was measured by Veeco Instrument Dektak ${ }^{3}$ surface profiler. The field emission scanning electron microscope (SEM) was taken with a HITACHI S-800 scanning electron microscope with $15 \mathrm{kV}$ accelerating voltage for imaging. Refractive indices of photosensitive PABO films formed on quartz substrates were measured at a wavelength of $1.320 \mu \mathrm{m}$ at room temperature with a Metricon model PC-2000 prism coupler. Using linearly-polarized laser with parallel (TE: transverse electric) and perpendicular (TM: transverse magnetic) polarization to the film plane, the in-plane $\left(n_{\mathrm{TE}}\right)$ and out-of-plane $\left(n_{\mathrm{TM}}\right)$ refractive indices and the film thickness of the samples were determined. The dielectric constant $(\varepsilon)$ at $1.0 \mathrm{MHz}$ frequency was calculated from the following equation: $\varepsilon=1.10 n_{\mathrm{AV}}^{2}$, where $n_{\mathrm{AV}}$ is average refractive index (i.e., $n_{\mathrm{AV}}=\left(2 n_{\mathrm{TE}}+\right.$ $\left.n_{\mathrm{TM}}\right) / 3$ ).

\section{RESULTS AND DISCUSSION}

\section{Synthesis of Cross-linker, $O B H B$}

The phenolic hydroxyl unit in MBHP increases moisture absorption that induces a high dielectric constant $(\varepsilon)$ of materials. To overcome this problem, MBHP should be replaced with a cross-linker without a phenol unit. A novel cross-linker, OBHB consisting of tetrafunctional benzylic alcohol moieties was designed and prepared as shown in Scheme 1. 4,4'-Oxydiphthalic anhydride (1) was treated with methanol and a catalytic amount of sulfuric acid to produce the corresponding tetramethyl ester derivative (2), which was converted to OBHB by reduction with LAH in dry THF in good yield.

\section{Synthesis of PAHA and PABO}

PAHA was synthesized by low temperature solution polycondensation, according to the previous paper. ${ }^{13}$ Such modification of PAHA by the insertion of bulky alicyclic moiety in the polymer backbone realizes a shift of the absorption to lower wavelength and lower dielectric constant, compared to wholly aromatic PHAs. The obtained PAHA showed 22,100 of $M_{\mathrm{w}}$ and 1.8 of polydispersity $\left(M_{\mathrm{w}} / M_{\mathrm{n}}\right)$ in GPC (DMF at $40^{\circ} \mathrm{C}$, calculated with polystyrene standards). PABO was prepared by thermal treatment at elevated temperature up to $350^{\circ} \mathrm{C}$ for $1 \mathrm{~h}$ under nitrogen as shown in Scheme 2. The satisfactory conversion from PAHA to PABO was confirmed by IR spectrum. 
(a)

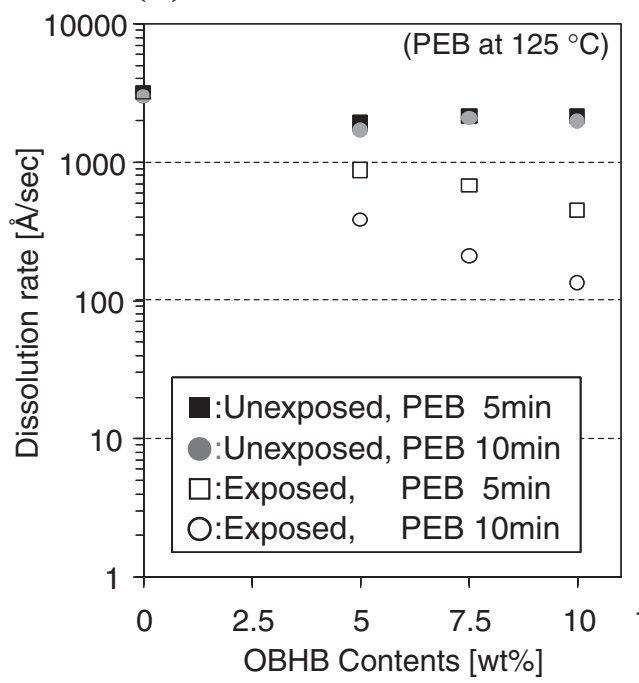

(b)

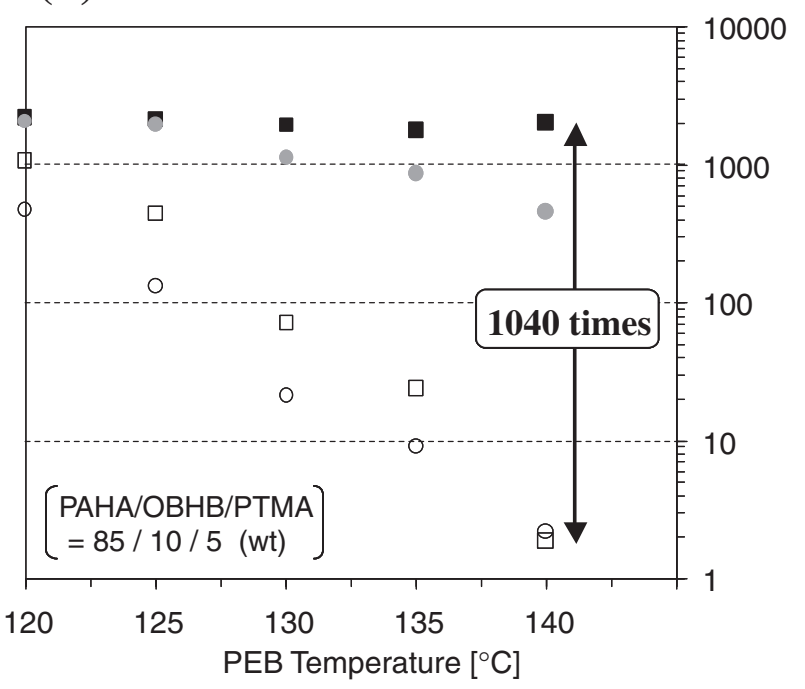

Figure 1. Dissolution rate of PSPABO as function of (a) OBHB contents and (b) post-exposure-bake-temperature. Other lithographic conditions were fixed as follows: (a) PAHA/PTMA $=85 / 5$ in weight, $\mathrm{PEB}$ at $125^{\circ} \mathrm{C}$; (b) $\mathrm{PAHA} / \mathrm{OBHB} / \mathrm{PTMA}=85 / 10 / 5$ in weight; both (a) and (b) $40 \mathrm{~mJ} / \mathrm{cm}^{2}$ of exposure to i-line, development with $2.38 \mathrm{wt} \%$ TMAHaq at $25^{\circ} \mathrm{C}$.

\section{Lithographic Evaluation in Negative-tone Chemically Amplification with $O B H B$}

As no absorption in the UV-vis spectrum of PAHA was observed above $320 \mathrm{~nm}$, PTMA having an absorption band extending to $450 \mathrm{~nm}$ was selected as a photoacid generator for photolithographic evaluation with i-line exposure $(365 \mathrm{~nm}) .{ }^{17}$ PTMA is more soluble in organic solvents such as cyclohexanone than DIAS which was used as a photoacid generator for the PosiPSPABO. The film was obtained from the solution of PAHA, OBHB and PTMA in cyclohexanone by spincast on a silicon wafer, and then pre-baked at $100^{\circ} \mathrm{C}$ for $2 \mathrm{~min}$ in air. To the photosensitive polymer film, a UV light at $365 \mathrm{~nm}$ (i-line) by a filtered super-highpressure mercury lamp was irradiated, followed by post-exposure bake (PEB) and development with $2.38 \mathrm{wt} \%$ of TMAHaq at $25^{\circ} \mathrm{C}$.

To clarify dissolution behaviors of the exposed and unexposed areas toward $2.38 \mathrm{wt} \%$ TMAHaq, the effects of OBHB loading and PEB temperature were studied and the results are shown in Figure 1. The dissolution rate was estimated from the change of the film thickness before and after the development. As shown in Figure 1a, the dissolution rate in the exposed area decreases with increasing the contents of OBHB up to $10 \mathrm{wt} \%$ both for $5 \mathrm{~min}$ and $10 \mathrm{~min}$ in PEB time. However, the dissolution difference between the exposed and unexposed areas is about 14 times at the $10 \mathrm{wt} \%$ OBHB loading. This dissolution contrast is not enough to obtain a clear pattern.

Cross-linking reactions between PAHA and OBHB are also promoted by PEB treatment in the chemical amplification resists. Thus, the effect of the PEB tem- perature was studied as shown in Figure 1b. Baking at $140^{\circ} \mathrm{C}$ for $5 \mathrm{~min}$ effectively reduces the dissolution rate of the exposed area, and the dissolution difference between the two areas reaches over 1000 times.

Based on these preliminary optimization studies, a photosensitive polymer system consisting of PAHA (85 wt \%), OBHB (10 wt \%), and PTMA (5 wt \%) was formulated. The photosensitivity curve of the formulated resist film in $2.2 \mu \mathrm{m}$ thickness is shown in Figure 2, where the PEB treatment was carried out

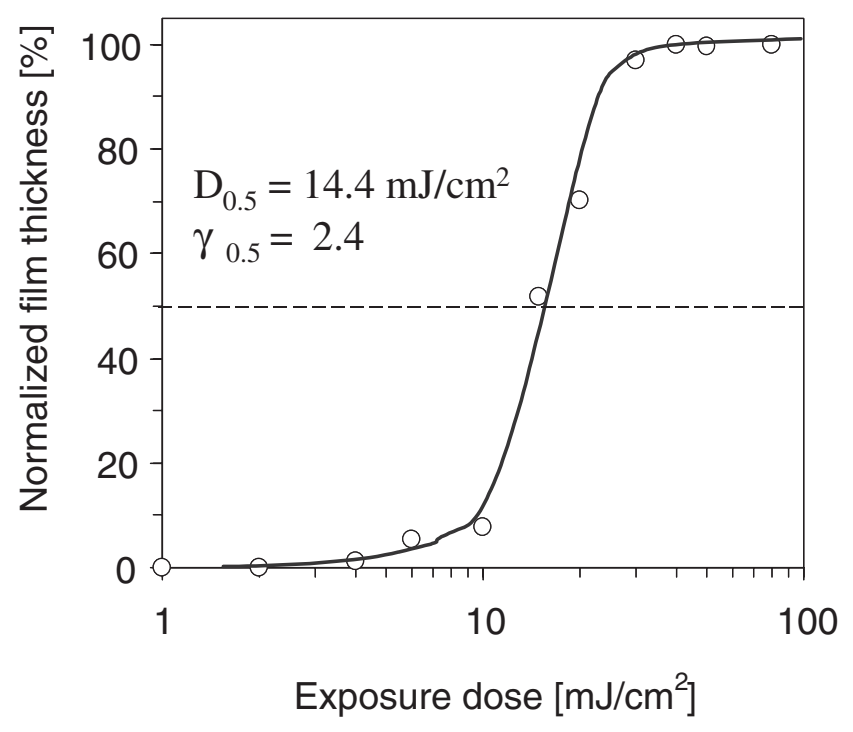

Figure 2. Characteristic sensitivity curve of Nega-PSPABO film $(2.2 \mu \mathrm{m}$ thickness) consisting of PAHA ( $85 \mathrm{wt} \%)$, OBHB $(10 \mathrm{wt} \%)$ and PTMA (5 wt \%). The film was pre-baked at 100 ${ }^{\circ} \mathrm{C}$ for $2 \mathrm{~min}$, post-exposure baked at $140{ }^{\circ} \mathrm{C}$ for $5 \mathrm{~min}$, and developed with $2.38 \mathrm{wt} \%$ TMAHaq at $25^{\circ} \mathrm{C}$ for $10 \mathrm{~s}$. 
at $140{ }^{\circ} \mathrm{C}$ for $5 \mathrm{~min}$. This resist system shows the high sensitivity $\left(D_{0.5}=14.4 \mathrm{~mJ} / \mathrm{cm}^{2}\right)$ and contrast $\left(\varepsilon_{0.5}=\right.$ 2.4) with $365 \mathrm{~nm}$ wavelength of light.

Figure 3 depicts a SEM image of a contact-printed pattern obtained with the $2.5-\mu \mathrm{m}$-thick resist film under the optimized conditions. A clear negative-tone

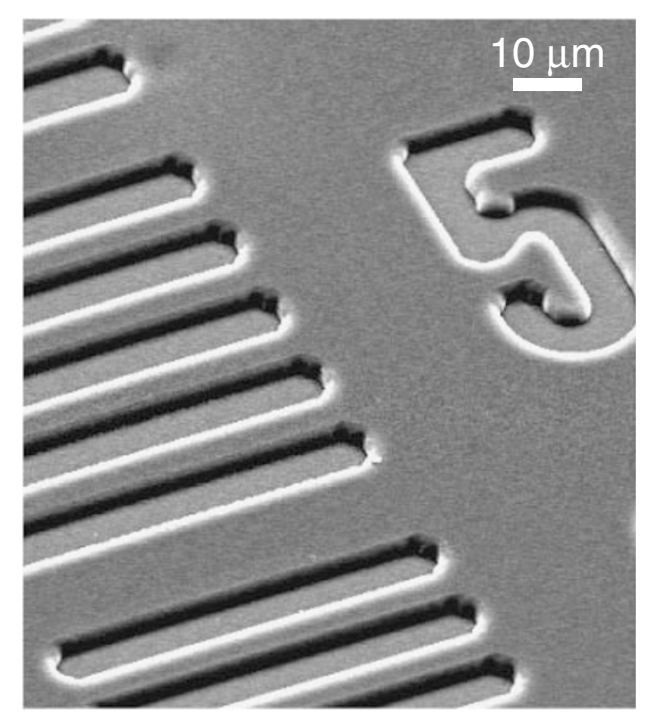

Figure 3. SEM image of the contact-printed film consisting of PAHA ( $85 \mathrm{wt} \%)$, OBHB (10 wt \%) and PTMA (5 wt \%) on a silicon wafer. In lithographic evaluation, the $2.5-\mu \mathrm{m}$-thick film was exposed to $80 \mathrm{~mJ} / \mathrm{cm}^{2}$ of i-line, developed with $2.38 \mathrm{wt} \%$ TMAHaq at $25^{\circ} \mathrm{C}$ for $14 \mathrm{~s}$ image with a $7 \mu \mathrm{m}$ line-and-space resolution can be observed.

\section{Mechanism of Cross-linking with $O B H B$}

To make clear the mechanism of the acid-catalyzed cross-linking, a model reaction was carried out using PAHA, $p$-methoxybenzyl alcohol (two equiv of PAHA) and $p$-toluenesulfonic acid monohydrate (pTS; $10 \mathrm{wt} \%$ of PAHA). The mixture of PAHA, $p$ methoxybenzyl alcohol and pTS in THF was cast on a laboratory dish, followed by heating at $100^{\circ} \mathrm{C}$ for $10 \mathrm{~min}$ and then at $140{ }^{\circ} \mathrm{C}$ for $10 \mathrm{~min}$ to mimic the pre-baking and post-baking steps in the resist processing. Finally, vacuum drying at $50^{\circ} \mathrm{C}$ for $2 \mathrm{~h}$ was carried out to remove the remained solvent. Figure 4 shows ${ }^{1} \mathrm{H}$ NMR spectra obtained after the baking steps with and without pTS. Without pTS, almost no change of the signals in the spectrum is observed (Figure 4a). In the presence of pTS, the characteristic methylene protons of the benzyl alcohol and phenolic hydroxyl protons of PAHA at 4.4 and $10.3 \mathrm{ppm}$, respectively (signal $m$ and $e$ in Figure 4a), disappear completely and $\mathrm{C}$-alkylated methylene protons at 3.7 ppm are formed (signal $y$ in Figure 4b).

These results indicate that a photogenerated acid catalyzes the formation of benzylic cation species, which undergo electrophilic substitution on the aromatic rings and the hydroxyl groups to produce $\mathrm{C}$ and O-alkylated polymers. The O-alkylated polymers
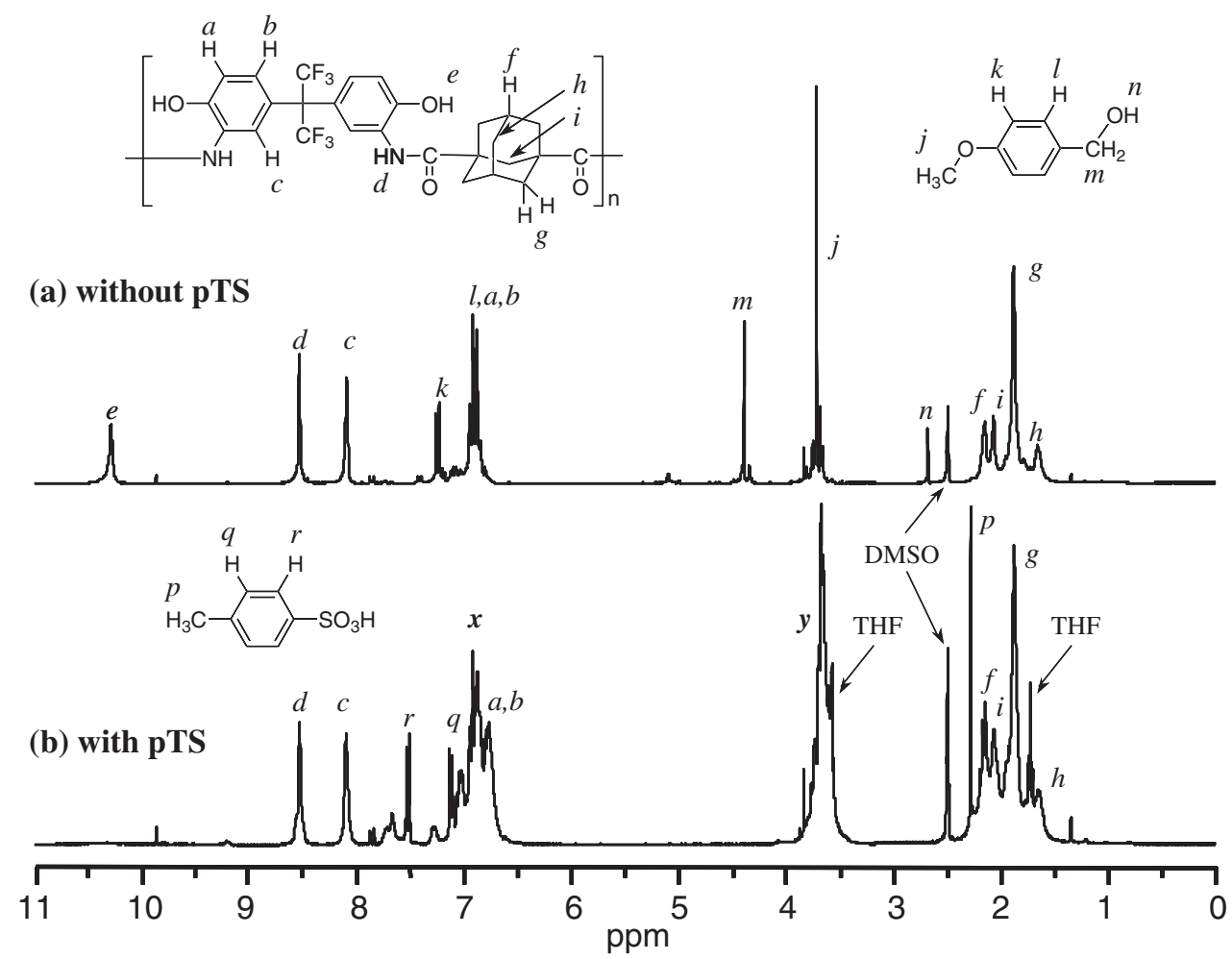

Figure 4. ${ }^{1} \mathrm{H}$ NMR spectra of PAHA film consisting of (a) p-methoxy benzyl alcohol, (b) p-methoxy benzyl alcohol and pTS in DMSO- $d_{6}$. Each film was baked at $100^{\circ} \mathrm{C}$ for $10 \mathrm{~min}$ and then $140{ }^{\circ} \mathrm{C}$ for $10 \mathrm{~min}$, followed by vacuum drying at $50^{\circ} \mathrm{C}$ for $2 \mathrm{~h}$. 


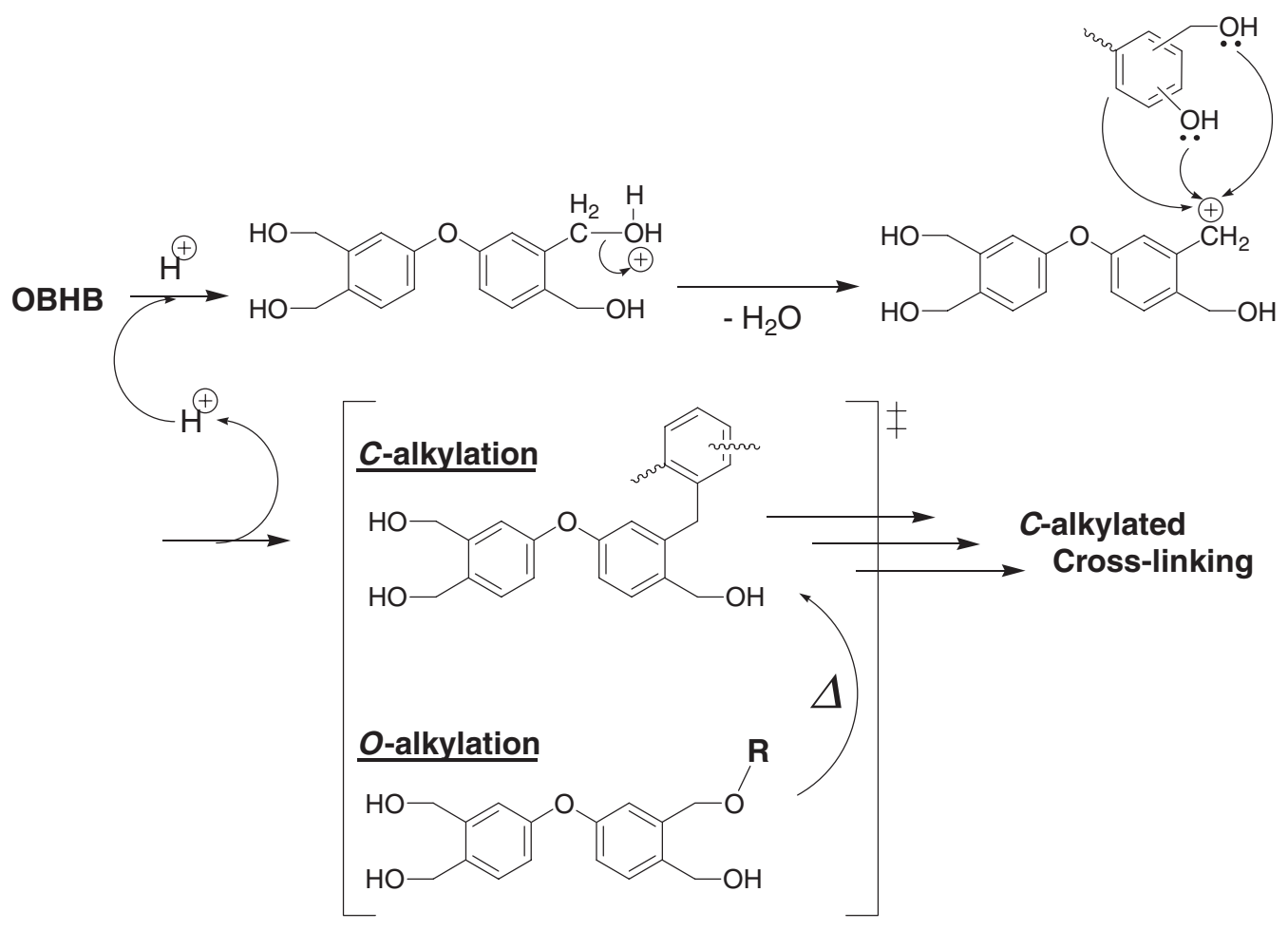

Scheme 3. Mechanism of acid-catalyzed cross-link reaction of OBHB.

are rearranged into the C-alkylated ones by heating. ${ }^{20,21}$ These reactions convert soluble PAHA into insoluble cross-linked polymers as shown in Scheme 3. Unlike MBHP in which the phenolic hydroxyl group is effective for the formation of benzylic cation as an electron-donating group, a promotion of the electrophilic substitution with OBHB may be attributed to the oxygen atom of ether linkage in OBHB as suggested by Lee et al. $^{22}$

\section{Thermal Stability of Photosensitive PABO}

The thermal stability of the patterned PABO was evaluated by thermogravimetry (TG). To convert PAHA into PABO, the cross-linked resist film was heated up to $350{ }^{\circ} \mathrm{C}$, held at that temperature for $1 \mathrm{~h}$ under nitrogen and cooled down to $50^{\circ} \mathrm{C}$, where the characteristic absorptions of hydroxyl and amide groups at 3400 and $1650 \mathrm{~cm}^{-1}$, respectively, disappeared in the IR spectrum. Figure 5a shows a TG curve of PSPABO. A $5 \%$ weight loss temperature $\left(T_{\mathrm{d} 5}\right)$ is observed at $468^{\circ} \mathrm{C}$ which is $50 \mathrm{~K}$ lower than that of the additive-free PABO $\left(518^{\circ} \mathrm{C}\right.$, Figure $\left.5 \mathrm{~b}\right) . .^{13}$ The lower $T_{\mathrm{d} 5}$ is attributed to remained additives such as OBHB and PTMA in the film, however, thermal stability over $450^{\circ} \mathrm{C}$ is enough high for the application to protector or insulator for VLSIs. Figure 6 shows a SEM image of PABO pattern after the thermal treatment up to $350{ }^{\circ} \mathrm{C}$ under nitrogen. No deformation of $7-\mu \mathrm{m}$-featured patterns was observed (Figure 3), where the final film thickness was shrunk from 4.7 to $4.1 \mu \mathrm{m}$ after the cure.

\section{Dielectric Constants of PABO Resist Films}

Refractive indices ( $n_{\mathrm{TE}}$ : in-plane, $n_{\mathrm{TM}}$ : out-ofplane) of a series of photosensitive PABO films on quartz plates were measured by using prism-coupler. From the refractive index $(n)$, dielectric constant of each resist film at $1 \mathrm{MHz}$ was estimated according to a modified Maxwell's equation $\left(\varepsilon \approx 1.1 \times n^{2}\right)$. The films of the PSPABOs were prepared by spin-cast

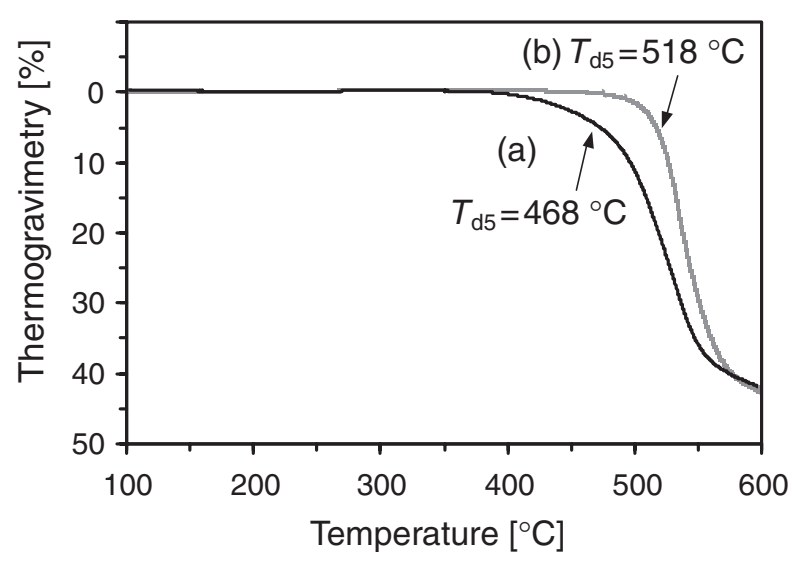

Figure 5. Thermogravimetry of (a) PSPABO film consisting of PAHA (85 wt \%), OBHB (10 wt \%) and PTMA (5wt \%), and (b) PABO film (ref 13). Each film was cured up to $350^{\circ} \mathrm{C}$ for $1 \mathrm{~h}$ under nitrogen. $5 \%$ weight loss temperatures $\left(T_{\mathrm{d} 5} \mathrm{~s}\right)$ are indicated beside each curve. 
from cyclohexanone solution on quartz plates, prebake $\left(100^{\circ} \mathrm{C}, 2 \mathrm{~min}\right)$, exposure to i-line $\left(100 \mathrm{~mJ} / \mathrm{cm}^{2}\right)$ and PEB $\left(140^{\circ} \mathrm{C}, 5 \mathrm{~min}\right)$, followed by the thermal treatment $\left(350^{\circ} \mathrm{C}, 1 \mathrm{~h}\right.$, under nitrogen) as a similar

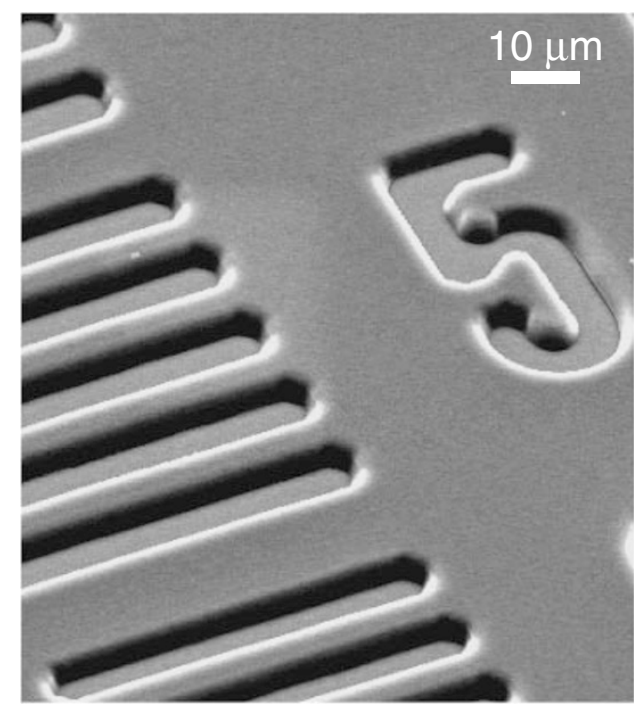

Figure 6. SEM image of cured PABO pattern on a silicon wafer. In lithographic evaluation, the film consisting of PAHA ( $85 \mathrm{wt} \%$ ), OBHB (10 wt \%) and PTMA (5 wt \%) was exposed to $80 \mathrm{~mJ} / \mathrm{cm}^{2}$ of i-line in contact-printing, developed with 2.38 wt $\%$ TMAHaq at $25^{\circ} \mathrm{C}$ for $14 \mathrm{~s}$. The patterned film was then cured at the elevated temperature up to $350^{\circ} \mathrm{C}$ and then hold at the temperature for $1 \mathrm{~h}$ under nitrogen, providing $4.1-\mu \mathrm{m}$-thick PABO film. way to lithographic evaluation investigated above.

Table I summarizes the measured refractive indices and the estimated dielectric constants of the PSPABO resist films compared with those of additive-free PABO and wholly aromatic PSPBO (Scheme 4) that were referred from the previous reports. ${ }^{13,16}$ As expected, the $\varepsilon$ value for Nega-PSPABO consisting of PAHA/OBHB/PTMA $(\varepsilon=2.62)$ is lower than that for Nega-PSPABO based on PAHA/MBHP/PTMA $(\varepsilon=2.67)$ because of no phenolic hydroxyl groups in OBHB.

\section{CONCLUSIONS}

Nega-PSPABO was formulated by mixing PAHA (85 wt \%), OBHB (10 wt \%) and PTMA (5 wt \%) in cyclohexanone, and functioned as an alkaline-developable chemically amplified PSPABO. Incorporation of the novel acid-catalyzed cross-linker based on benzylic alcohol, OBHB, into the Nega-PSPABO resist system induces not only high photosensitivity $\left(D_{0.5}=14 \mathrm{~mJ} / \mathrm{cm}^{2}\right.$ of i-line $)$, but also the lower dielectric constant of the matrix polymer (optically estimated $\varepsilon=2.62$ ) due to the absence of phenolic hydroxyl groups in OBHB. The cross-link reaction employed with OBHB undergoes through electrophilic substitution on the matrix polymer and itself based on the ${ }^{1} \mathrm{H}$ NMR study. The negative image was converted into the corresponding $\mathrm{PABO}$ image by the thermal treatment with clear $7-\mu \mathrm{m}$-featured patterns.

Table I. Refractive indices and optically estimated dielectric constant of photosensitive polybenzoxazoles

\begin{tabular}{|c|c|c|c|c|c|}
\hline \multirow{2}{*}{ Film } & \multirow{2}{*}{$\begin{array}{l}\text { Thickness } \\
\quad(\mu \mathrm{m})\end{array}$} & \multicolumn{3}{|c|}{ Refractive index } & \multirow{2}{*}{$\frac{\text { Dielectric constant }}{\varepsilon^{\mathrm{d}}}$} \\
\hline & & $n_{\mathrm{TE}}{ }^{\mathrm{a}}$ & $n_{\mathrm{TM}}^{\mathrm{b}}$ & $n_{\mathrm{AV}}{ }^{\mathrm{c}}$ & \\
\hline PABO & 6.5 & 1.5244 & 1.5211 & 1.5233 & 2.55 \\
\hline Nega-PSPABO-I ${ }^{\mathrm{e}}$ & 6.5 & 1.5436 & 1.5394 & 1.5422 & 2.62 \\
\hline Nega-PSPABO-II ${ }^{\mathrm{f}}$ & 4.6 & 1.5705 & 1.5334 & 1.5581 & 2.67 \\
\hline Nega-PSPBO ${ }^{g}$ & 4.1 & 1.5828 & 1.5738 & 1.5798 & 2.75 \\
\hline
\end{tabular}

${ }^{\mathrm{a}}$ In-plane refractive index measured by prism coupler. ${ }^{\mathrm{b}}$ Out-of-plane refractive index by prism coupler. ${ }^{\mathrm{c}}$ Average refractive index calculated as following equation: $n_{\mathrm{AV}}=\left(2 n_{\mathrm{TE}}+n_{\mathrm{TM}}\right) / 3 .{ }^{\mathrm{d}}$ dielectric constant

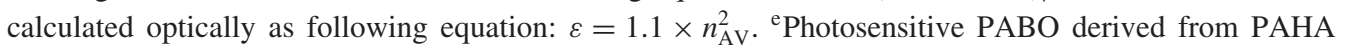
( $85 \mathrm{wt} \%)$, OBHB (10 wt \%) and PTMA $(5 \mathrm{wt} \%)$. The film on a quartz was exposed to i-line and postexposure baked at $140{ }^{\circ} \mathrm{C}$ for $10 \mathrm{~min}$, followed by cure at $350{ }^{\circ} \mathrm{C}$ for $1 \mathrm{~h}$ under nitrogen. ${ }^{\mathrm{f}}$ Photosensitive PABO derived from PAHA ( $85 \mathrm{wt} \%)$, MBHP (10 wt \%) and PTMA (5 wt \%). The film preparation was

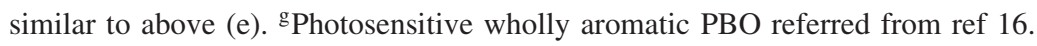

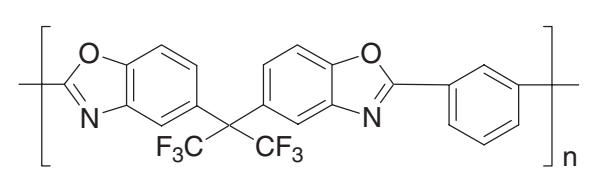

PBO<smiles>OCc1cc(Cc2cc(CO)c(O)c(CO)c2)cc(CO)c1O</smiles>

MBHP<smiles>CCCS(=O)(=O)O/N=C1\C=C/C(=C(/C#N)c2ccccc2C)S1</smiles>

PTMA

Scheme 4. Components for previous negative-tone PSPBO with wholly aromatic polymer (ref 16). 


\section{REFERENCES}

1. D. N. Khanna and W. H. Mueller, Polym. Eng. Sci., 29, 954 (1989).

2. H. Ahne, A. Hammerschmidt, and E. Schmidt, Proc. Polym. Mater. Sci. Eng., ACS, 60, 629 (1989).

3. R. Rubner, A. Hammerschmidt, R. Leuschner, and H. Ahne, in "Polym. Microelectron. Proc. Int. Symp," Y. Tabata, Ed., Kodansha, Tokyo, 1990, p 789.

4. R. Rubner, Adv. Mater., 2, 452 (1990).

5. T. Yamaoka, N. Nakajima, K. Koseki, and Y. Murayama, J. Polym. Sci., Part A: Polym. Chem., 28, 2517 (1990).

6. T. Banba, E. Takeuchi, A. Tokoh, and T. Takeda, "Proc. Electr. Compon. Conf., IEEE," 1991, p 564.

7. H. Ahne, R. Rubner, and R. Sezi, Appl. Surf. Sci., 106, 311 (1996).

8. R. Sezi, A. Maltenberger, W. Radlik, G. Shmid, A. Weber, and K. Buschick, Proc. SPIE, 3582, 236 (1998).

9. D. F. Huang, J. Y. Chiou, C. C. Hung, and B. R. Young, Proc. SPIE, 4277, 375 (2001).

10. K. Ebara, Y. Shibasaki, and M. Ueda, Polymer, 44, 333 (2003).

11. K. Fukukawa, Y. Shibasaki, and M. Ueda, Polym. J., 36, 489 (2004).
12. G. Maier, Prog. Polym. Sci., 26, 3 (2001).

13. K. Fukukawa, Y. Shibasaki, and M. Ueda, Macromolecules, 37, 8256 (2004).

14. K. Takeshi, K. Okuyama, Y. Ohba, and M. Ueda, J. Photopolym. Sci. Technol., 13, 345 (2000).

15. K. Tsuchiya, Y. Shibasaki, M. Suzuki, and M. Ueda, J. Polym. Sci., Part A: Polym. Chem., 42, 2235 (2004).

16. K. Fukukawa, K. Ebara, Y. Shibasaki, and M. Ueda, in "Advances in Imaging Materials and Processes" H. Ito, P. R. Varanasi, M. M. Khojasteh and R. Chen, Ed., Society of Plastic Engineers, Mid-Hudson Section, New York, N.Y., 2003, p 339.

17. T. Asakura, H. Yamato, and M. Ohwa, J. Photopolym. Sci. Technol., 13, 223 (2001).

18. K. Lenghaus, G. G. Qiao, and D. H. Solomon, Polymer, 42, 3355 (2001).

19. H. Seino, K. Iguchi, O. Haba, Y. Ohba, and M. Ueda, Polym. J., 31, 822 (1999).

20. S. M. Lee and M. J. Fréchet, Macromolecules, 27, 5160 (1994).

21. M. Ueda and T. Nakayama, Macromolecules, 29, 6427 (1996).

22. S. M. Lee, M. J. Fréchet, and C. G. Willson, Macromolecules, 27, 5154 (1994). 